\title{
Nerves Control Redox Levels in Mature Tissues Through Schwann Cells and Hedgehog Signaling
}

\author{
Francesca Meda, ${ }^{1-3,{ }^{*}}$ Carole Gauron, ${ }^{1,3, *}$ Christine Rampon, ${ }^{1,3,4, *}$ Jérémie Teillon, ${ }^{1,3}$ \\ Michel Volovitch, ${ }^{1-3}$ and Sophie Vriz ${ }^{1,3,4}$
}

\begin{abstract}
Aims: Recent advances in redox biology have emphasized the role of hydrogen peroxide $\left(\mathrm{H}_{2} \mathrm{O}_{2}\right)$ in the modulation of signaling pathways and revealed that $\mathrm{H}_{2} \mathrm{O}_{2}$ plays a role in cellular remodeling in adults. Thus, an understanding of the mechanisms that control $\mathrm{H}_{2} \mathrm{O}_{2}$ levels in mature tissue would be of great interest. Results: We used a denervation strategy to demonstrate that sensory neurons are responsible for controlling $\mathrm{H}_{2} \mathrm{O}_{2}$ levels under normal conditions and after being lesioned. Moreover, we demonstrate that severed nerves respond to appendage amputation via the induction of Hedgehog signaling and that this signaling is responsible for $\mathrm{H}_{2} \mathrm{O}_{2}$ production in the wounded epidermis. Finally, we show that $\mathrm{H}_{2} \mathrm{O}_{2}$ and nerve growth are regulated via reciprocal action in adults. Innovation and Conclusion: These data support a new paradigm for the regulation of tissue homeostasis: $\mathrm{H}_{2} \mathrm{O}_{2}$ attracts nerves and nerves control $\mathrm{H}_{2} \mathrm{O}_{2}$ levels in a positive feedback loop. This finding suggests that the peripheral nerve redox environment could be a target for manipulating cell plasticity in adults. Antioxid. Redox Signal. 24, 299-311.
\end{abstract}

\section{Introduction}

$\mathbf{R}$ eactive oxygen SPECIES (ROS) have long been considered deleterious compounds that induce pathological situations by damaging biological molecules (DNA, proteins, and lipids). It is becoming increasingly clear that ROS, which are constantly produced at various levels by virtually all cells, also contribute to physiological processes $(11,43,47,54)$, mainly by causing cysteine modifications in signaling proteins $(14,41)$. The redox state of a tissue results from a complex balance between the production and degradation of oxidative molecules (58). Unchecked ROS levels have been identified in many pathological conditions, including neurodegenerative disorders, aging, and cancer, as illustrated by the development of pro- and antioxidant therapeutic strategies to treat cancer $(2,18)$.
Of the ROS, hydrogen peroxide $\left(\mathrm{H}_{2} \mathrm{O}_{2}\right)$ has a long life span and participates in redox signaling, and it has recently been demonstrated that a transient increase in $\mathrm{H}_{2} \mathrm{O}_{2}$ is necessary for inducing a regenerative program in Xenopus larvae (29), adult zebrafish $(15,20)$, and mice $(1)$, as well as for enhancing cell plasticity $(4,53)$. Reciprocal interactions between $\mathrm{H}_{2} \mathrm{O}_{2}$ and nerves are suggested by two observations: $\mathrm{H}_{2} \mathrm{O}_{2}$ enhances peripheral sensory axon growth in wounded caudal fins of zebrafish larvae (44), and efficient epidermal wound healing requires the presence of sensory neurons $(21,52)$. In addition, innervation has been demonstrated to be essential for launching a regenerative program in adults $(16,25,50)$. Caudal fin regeneration in adult zebrafish therefore appears to be a suitable model in which to study the relationship between nerves and tissue redox status. Indeed, $\mathrm{H}_{2} \mathrm{O}_{2}$ production starts soon after fin amputation, and it is necessarily

\footnotetext{
${ }^{1}$ Centre Interdisciplinaire de Recherche en Biologie (CIRB) CNRS UMR 7241/INSERM U1050/Collège de France, Paris, France.

${ }^{2}$ École Normale Supérieure, Institute of Biology at the Ecole Normale Supérieure (IBENS), CNRS UMR8197, INSERM U1024, Paris, France.

${ }^{3}$ PSL Research University, Paris, France.

${ }^{4}$ Biology Department, Université Paris Diderot, Sorbonne Paris Cité, Paris Cedex 13, France.

*These authors contributed equally to this work.

(C) Francesca Meda et al. 2015; Published by Mary Ann Liebert, Inc. This Open Access article is distributed under the terms of the Creative Commons Attribution Noncommercial License (http://creativecommons.org/licenses/by-nc/4.0/) which permits any noncommercial use, distribution, and reproduction in any medium, provided the original author(s) and the source are credited.
} 


\section{Innovation}

The present study demonstrates that redox levels in mature tissue are controlled by sensory nerves via Hedgehog signaling. In a positive feedback loop, hydrogen peroxide $\left(\mathrm{H}_{2} \mathrm{O}_{2}\right)$ stimulates nerve growth and the Shh pathway. This finding not only identifies cooperation between nerves, $\mathrm{H}_{2} \mathrm{O}_{2}$, and Hedgehog signaling to ensure tissue homeostasis and repair in adults but also provides a tractable mechanism for the wound healing deficiency associated with neuropathies.

maintained while cells of various lineages in the stump respond to the injury by dedifferentiating and acquiring progenitor identities $(15,20)$.

We previously showed that in this context, ROS induce apoptosis, which in turn stimulates progenitor recruitment and proliferation through a purinergic signaling pathway (40). Progenitor cells subsequently accumulate at the damaged surface underneath the wound epithelium from 15 to 36 hours postamputation (hpa) and form a mass of proliferating cells, the blastema that is clearly visible at $48 \mathrm{hpa}$ (38). The missing fin is then replaced through blastema growth, differentiation, and morphogenesis.

The present article addresses the control of $\mathrm{H}_{2} \mathrm{O}_{2}$ levels by nerves and the reciprocal action of $\mathrm{H}_{2} \mathrm{O}_{2}$ on nerve growth in adults in normal conditions and after lesioning. To determine the relationship between $\mathrm{H}_{2} \mathrm{O}_{2}$ and nerves, we first developed a model in which we measure levels of ROS (specifically $\mathrm{H}_{2} \mathrm{O}_{2}$ ) after denervation of the adult caudal fin, and we then coupled this assay with manipulation of $\mathrm{H}_{2} \mathrm{O}_{2}$ levels and signaling pathway analysis. In this study, we demonstrate that in adult zebrafish, sensory nerves are involved in the control of redox levels both in normal mature tissue and following injury. Moreover, we show that Schwann cells (SCs), through Shh signaling, mediate this control of redox status by nerves. Finally, we also demonstrate that $\mathrm{H}_{2} \mathrm{O}_{2}$ stimulates nerve growth in adults. Our results suggest that nerves control tissue redox levels and $\mathrm{H}_{2} \mathrm{O}_{2}$ attracts nerves in a positive feedback loop and that this feedback loop is involved in tissue homeostasis.

\section{Results}

\section{Nerve remodeling after injury}

Adult zebrafish caudal fins primarily contain sensory neurons as the fin does not contain muscle. Axons, which are fasciculated inside the rays in the uninjured fin, defasciculate as early as 6 hpa when Wallerian degeneration begins (Fig. 1). This tip degeneration of the sectioned nerves, which is ac- companied by axonal skeleton disintegration and the disappearance of acetylated tubulin staining, is much faster than in mammals; in zebrafish, axon regrowth is clearly visible at $15 \mathrm{hpa}$. Before $18 \mathrm{hpa}$, cell proliferation occurs mostly in the epidermis/dermis of the stump and mainly involves epidermal cells and SCs (40). We therefore used an antiphosphorylated histone $\mathrm{H} 3$ antibody to count proliferating Schwann and epidermal cells during nerve remodeling (Fig. 1D-I). Proliferation is strongly enhanced during axon regrowth (Fig. 1F-H). Nerve remodeling involves systemic activation of Sox 10 in SCs shortly after amputation (Fig. 2) and local activation after lesion (Supplementary Fig. S1; Supplementary Data are available online at www.liebertpub.com/ars). It is worth noting that in uncut fins, only some of the most distal SCs are positive for Sox 10 (Fig. 2B). By 18-24 hpa, the axons (Fig. 1G, H) and the first blastemal cells (40) have reached the wound epidermis, and ROS levels in the wound epidermis have decreased (15). These data reveal dynamic degeneration and regrowth of sensory axons, as well as activation of SCs, within the first $24 \mathrm{~h}$ of amputation.

\section{Nerves control redox levels in mature tissue}

To dissect the involvement of nerve tracks in $\mathrm{H}_{2} \mathrm{O}_{2}$ regulation and the establishment of a regenerative field, we developed a denervation assay (Fig. 3A-C). At the base of the caudal fin, sensory neurons are fasciculated and split into two branches, with one branch innervating the dorsal part and one innervating the ventral part of the fin. We performed a resection of the dorsal branch at the time of amputation (Fig. 3A) and verified the efficiency of the surgery by testing for the presence of axons with acetylated tubulin staining 3 days postamputation (dpa) (Fig. 3B) and quantifying the effect of denervation on the size of the regenerated fin (Fig. 3C). Denervation abolished the regenerative capacity of the amputated caudal fin. We then used this assay to determine whether peripheral nerves influence the tissue redox status in mature tissue. ROS detection was performed $16 \mathrm{~h}$ postdenervation in nonamputated fins. The nondenervated part of the adult caudal fin is mainly in a reduced state (Fig. 3E, G), but denervation induced a twofold increase in the ROS levels in the tissue (Fig. 3F, G). Thus, peripheral nerves control redox status in this mature tissue.

\section{Nerves control redox levels after amputation}

When the caudal fin was amputated, a substantial and sustained production of $\mathrm{H}_{2} \mathrm{O}_{2}$ was observed (15) (Fig. 3H). To test the involvement of nerves in this lesion-induced ROS production, we combined the denervation assay with amputation and measured ROS production over time (experimental scheme presented in Supplementary Fig. S2). We

FIG. 1. Wallerian degeneration and axon growth after amputation are very rapid in adult fish. (A) Scheme of the experiment. (B-I) Caudal fins of adult fish were amputated ( $t=0$, blue arrow), and the axon cytoskeleton (green) and mitosis (white) were visualized over time through immunofluorescence staining for the axonal marker, acetylated tubulin (green), and phosphorylated histone H3 (white), respectively. $\left(\mathbf{D}^{\prime}, \mathbf{E}^{\prime}, \mathbf{H}^{\prime}\right)$ Show higher magnifications of the distal parts of (D, E, H), respectively. At 6 hpa, the extremities of the axons begin to be fragmented, and the nerves begin to defasciculate; at $10 \mathrm{hpa}$, defasciculation is more pronounced. During Wallerian degeneration (10-12 hpa), epidermal and SCs start to proliferate. At $15 \mathrm{hpa}$, axons have regrown, and some axons cross the amputation plane at $18 \mathrm{hpa}$. Dotted line: amputation plane. Dashed line: distal part of the fin. Before $24 \mathrm{hpa}$, the amputation plane corresponds to the distal part of the fin. For each time point, the most distal part of the fin (upper panel) and a proximal part (lower panel) are shown. Scale bars $=50 \mu M$. hpa, hours postamputation; SCs, Schwann cells. To see this illustration in color, the reader is referred to the web version of this article at www.liebertpub.com/ars 


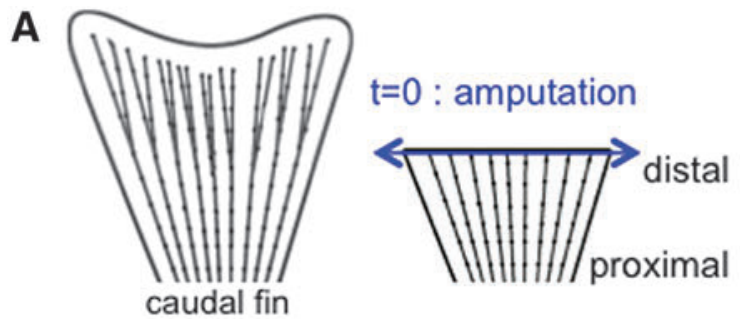

Fixation upon time

Detection of acetylated tubulin

and phosphorylated histone $\mathrm{H} 3$
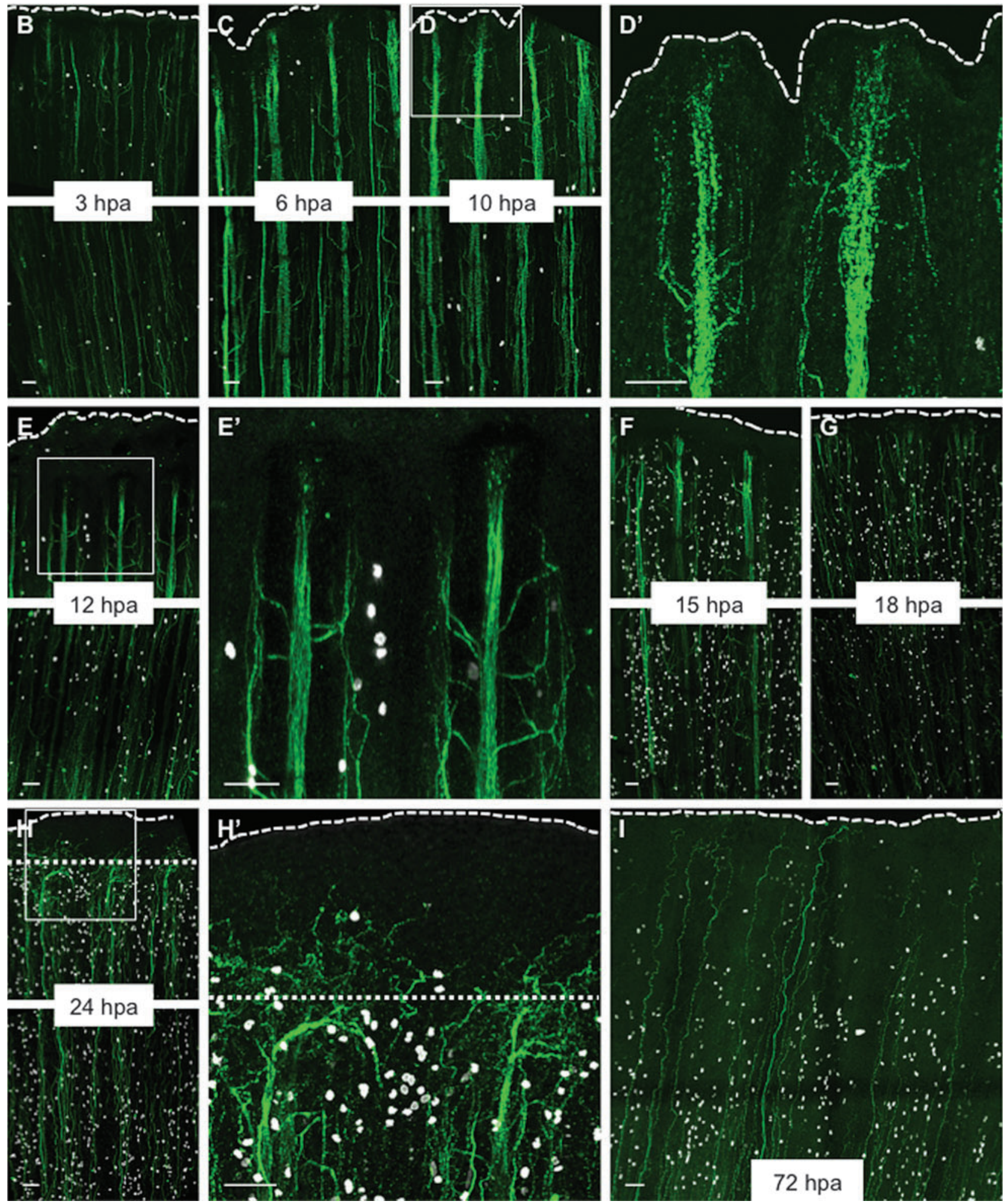
A $\quad t=0$ : amputation
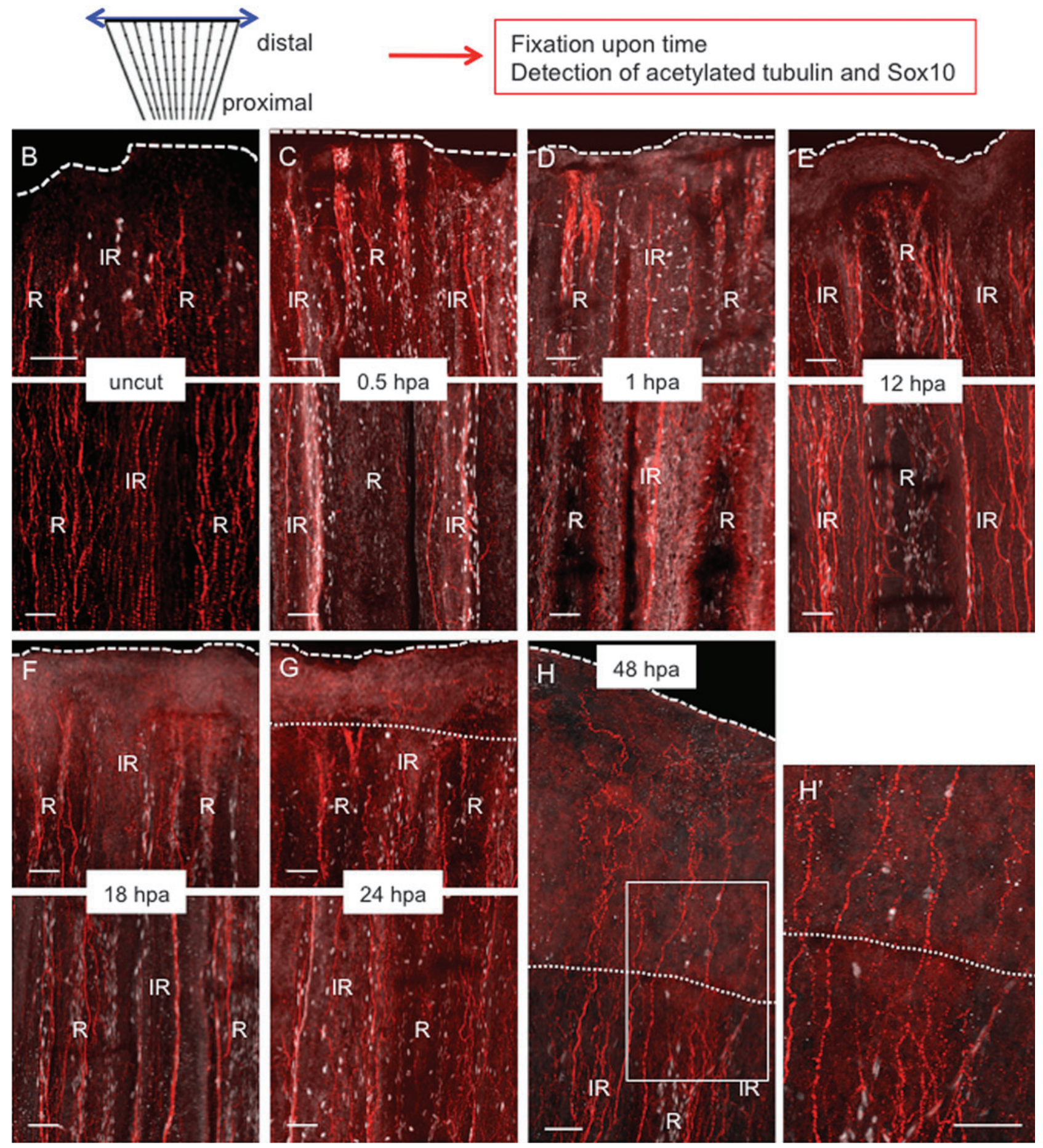

FIG. 2. Systemic Sox10 activation in SCs following amputation. (A) Scheme of the experiment. (B-H) Caudal fin of adult fish was amputated $(t=0$, blue arrow), and the axon cytoskeleton ( red) and immature SCs (white) were visualized over time through immunofluorescence staining for the axonal marker, acetylated tubulin (red), and the immature SC marker, Sox10 (white), respectively. Immunostaining in uncut fin (B) or after amputation (C-H). (B-G) The upper panel shows the distal part of the amputated fin, and the lower panel shows a more proximal part. $\left(\mathbf{H}^{\prime}\right)$ Shows a higher magnification of $(\mathbf{H})$. Dotted line: amputation plane. Dashed line: distal part of the fin. Scale bars $=50 \mu M$. R, ray; IR, inter-ray. To see this illustration in color, the reader is referred to the web version of this article at www.liebertpub.com/ars

subsequently denervated the dorsal part of the caudal fin and examined the ROS induced by amputation at $1 \mathrm{hpa}$ (fin amputated $16 \mathrm{~h}$ postdenervation; Supplementary Fig. S2C and Fig. 3J) and $17 \mathrm{hpa}$ (fin amputated at the time of denervation;
Supplementary Fig. S2B and Fig. 3H, I, K). Denervation reduced the redox levels at the tip of the fin, the major site of ROS production after amputation, during both the immediate response (1 hpa) and the sustained production of ROS 

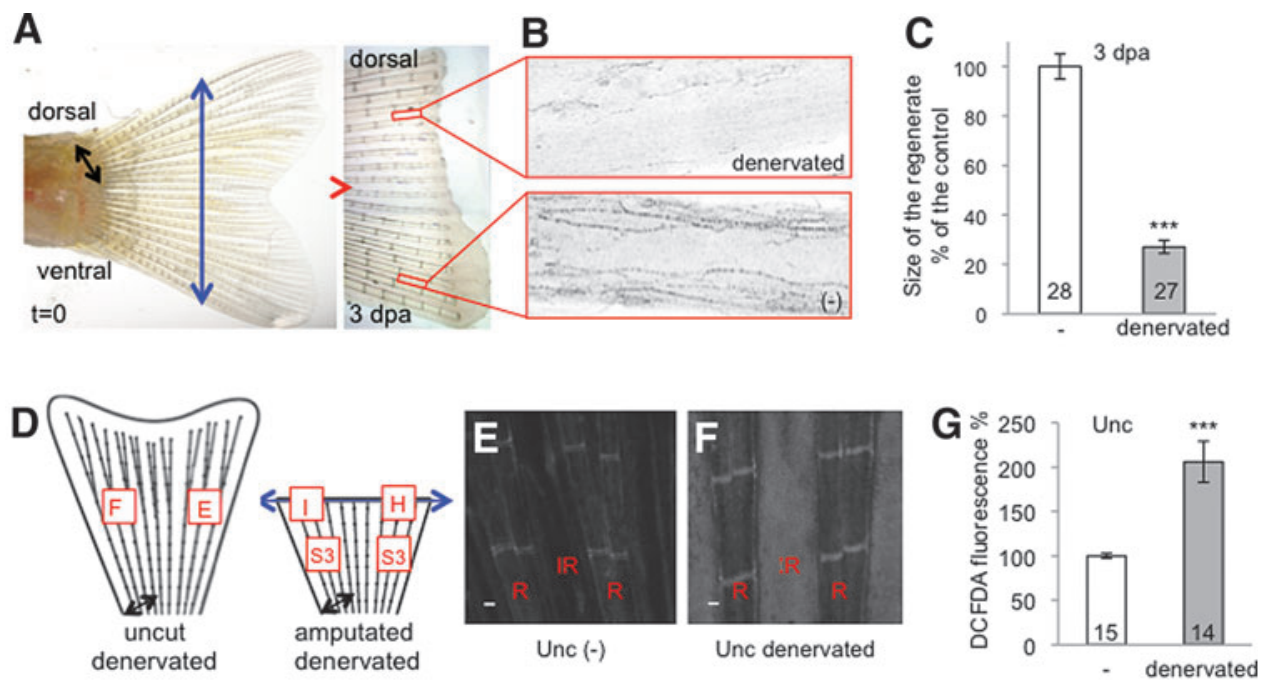

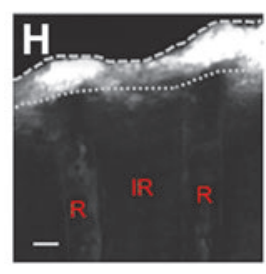

17 hpa (-)

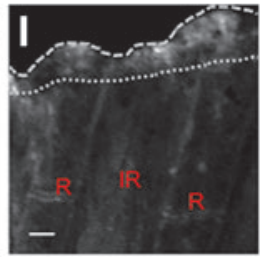

17 hpa denervated
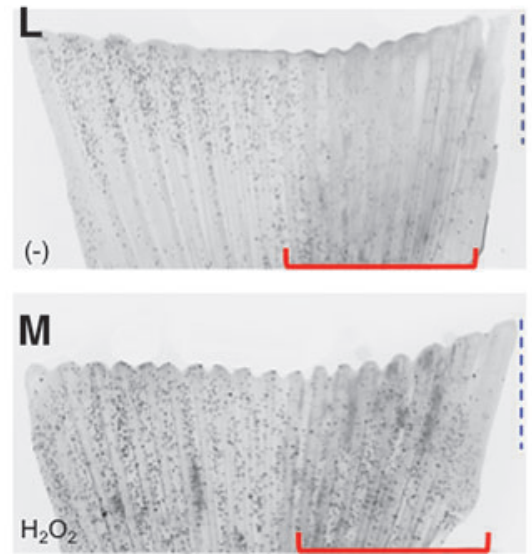
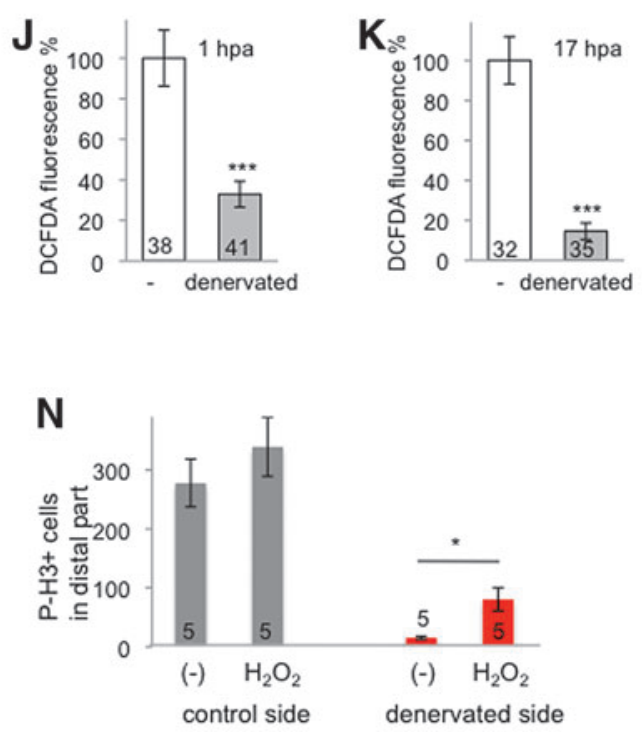

FIG. 3. Sensory neurons control ROS levels in the adult caudal fin. (A) The dorsal part of the caudal fin was denervated (black arrow) at the time of amputation (blue arrow). At $3 \mathrm{dpa}$, the dorsal part (denervated) had not regenerated compared with the ventral part (-) (representative image). (B) At 3 dpa, antiacetylated tubulin staining indicates the absence of axons in the denervated part. (C) Quantification of the size of the regenerated tissue at $3 \mathrm{dpa}$ in the control (-) and denervated parts. The efficiency of regeneration is expressed as a percentage of the control. (D) Schematic representation of ROS detection in fin denervated in the dorsal part, with and without amputation. The squares indicate the position of ROS measurement, and the letters refer to panels in this figure or Supplementary Figure S3. (E-G) ROS detection at the level of the first ray bifurcation in an uncut fin. (H-K) ROS detection at the level of the amputation plane at 1 and $17 \mathrm{hpa}$. (H, I) Representative images at $17 \mathrm{hpa}$. (L-N) Mitotic cells were stained with antiphosphorylated histone $\mathrm{H} 3$ at $24 \mathrm{hpa}$ in fins denervated at the time of amputation on the dorsal part (red line) and incubated in water (L) or $1 \mathrm{mM}$ $\left(\mathrm{H}_{2} \mathrm{O}_{2}\right)(\mathbf{M})$. Quantification of proliferation was performed on the distal part of the fin (blue dashed line) in the control part or the denervated part (red line) $(\mathbf{N})$. The red line indicates the denervated part. (H, I) Dotted line: amputation plane. Dashed line: distal part of the fin. Error bars represent the SEM $(* p<0.05 ; * * *<0.001) . n$ Values are indicated at the bottom of each column of the graphs. Scale bars $=50 \mu M$. A scheme of the different conditions in which ROS were measured is given in Supplementary Figure 2. dpa, days post amputation; $\mathrm{H}_{2} \mathrm{O}_{2}$, hydrogen peroxide; ROS, reactive oxygen species; SEM, standard error of the mean. To see this illustration in color, the reader is referred to the web version of this article at www.liebertpub.com/ars 
(17 hpa) (Fig. 3H-K). However, far from the amputation plane, that is, in the stump, denervation had the same effect as in the uncut fins; it induced a mild increase in the redox levels at all stages (Supplementary Fig. S3). Cell proliferation in the epidermal compartment is a prerequisite to regeneration (40). At $24 \mathrm{hpa}$, proliferation concerned dermal and epidermal cells of the distal part of the fin (six segments from the amputation plane). Cell proliferation in the stump at 24 hpa was strongly inhibited by denervation (Fig. 3L, N). Addition of $\mathrm{H}_{2} \mathrm{O}_{2}$ in water enhanced proliferation in the control part of the fin (nondenervated) and extended the domain of proliferation to the more proximal part of the fin, suggesting that the entire epidermis is able to answer to $\mathrm{H}_{2} \mathrm{O}_{2}$ (Fig. 3M). Moreover, addition of $\mathrm{H}_{2} \mathrm{O}_{2}$ was sufficient to partially reverse the inhibition of proliferation induced by denervation (Fig. 3M, N). In conclusion, denervation of the appendage induced a twofold increase in oxidative levels on a global scale, while it strongly inhibited the large and sustained injury-induced increase in ROS in the wound epidermis. As expected, denervation in zebrafish also inhibited further steps of regeneration (i.e., proliferation in the stump), and this inhibition could be reversed by addition of $\mathrm{H}_{2} \mathrm{O}_{2}$ (Fig. 3N). Thus, peripheral nerves constrain the tissue redox level in mature tissue and they are also involved in the modification of ROS levels induced by wounding and amputation.

\section{Hedgehog signaling and SCs participate in redox control}

The vertebrate peripheral nervous system is able to regenerate (10). This remarkable property is mainly dependent on SCs, which have a high degree of plasticity and dedifferentiate to progenitor or stem cells after nerve damage (46). During dedifferentiation, SCs provide signals that transform the environment to one that supports axon growth and guides axons to the distal stump (35). Several signals are likely to be involved in the rapid reprogramming and proregenerative properties of glial cells after neuronal injury. For instance, Hedgehog signaling appears to be a good candidate because it has been proven to be a key element in the definition of a niche that favors activation of glial cells or, more generally, stem cells in both central and peripheral axon regeneration (7, 42, 51). Furthermore, Hedgehog is regulated by Sox 10, the expression of which is induced shortly after nerve lesions (Fig. 2 and Supplementary Fig. S1). Moreover, Hedgehog signaling is directly involved in osteoblast proliferation during late stages of caudal fin regeneration (from 2 to $7 \mathrm{dpa}$ ) $(39,60)$ and in heart regeneration $(55)$, and it has recently been proposed that peripheral nerve-derived Hedgehog might be involved in non-neuronal tissue regeneration $(7,36,61)$.

We took advantage of a transgenic line that recapitulates sonic hedgehog expression in adult fish (shh:green fluorescent protein [GFP]) $(13,60)$ to follow shh expression after amputation. To enable the very early detection of $s h$ locus activity, we resorted to anti-GFP staining rather than imaging direct reporter fluorescence. In agreement with previous observations (60), a group of Shh-positive cells was localized at the end of each ray in the mature uncut fin (Fig. 4B). Axon staining with an antiacetylated tubulin antibody indicated that the Shh-positive cells crown the axons of peripheral sensory neurons (Fig. 4B). This group of cells disappeared after denervation (Fig. 4C, D), which suggests that they are nerve dependent or part of the nerve. It is unclear whether these cells originate from the mesoderm or the neural crest (19). To test whether they could be derived from SCs, we performed coimmunostaining for GFP and Sox 10 shortly after amputation of the adult caudal fin (at 0.5 hpa [Fig. 4E$\mathrm{G}$ ] or at $12 \mathrm{hpa}$ [Fig. $4 \mathrm{H}, \mathrm{I}]$ ). The adult caudal fin contains few types of neural crest-derived cells, including SCs and melanophores (Supplementary Fig. S4). To avoid confusion, the coimmunostaining was performed in the nacre strain of fish, which lack neural crest-derived melanophores. Confocal images of the whole fin (Fig. 4E-G) or cryosections (Fig. 4H, I) indicated that the Shh-positive cells were also Sox10 positive and therefore were derived from the neural crest. We subsequently analyzed the behavior of these cells during regeneration (Fig. 5). GFP was detected in a subpopulation of activated SCs shortly after amputation (Fig. 5B). This shh expression was also observed in SCs activated by skin lesions as soon as $15 \mathrm{~min}$ after lesion (Supplementary Fig. S1). After amputation, Shh-expressing cells changed shape and position during Wallerian degeneration, and some cells in the interrays migrated to the tip of the amputated fin while the axons regrew (Fig. 5E, F). By 72 hpa, most of the Shh-expressing cells were localized at the tip of the hemirays and reformed the pools of cells (Fig. 5H) that were later responsible for osteoblast proliferation (39). Thus, shortly after amputation or lesioning, activated SCs begin to express Sox10 and some cells induce Shh expression. Shh-positive cells migrate to the tip of the fin while axons regrow and they form groups of cells that crown the axons.

To test the role of Shh in the very first events following amputation (before $24 \mathrm{hpa}$ ), we disrupted Hedgehog signaling with cyclopamine (HH-i) (Fig. 6). $\mathrm{HH}-\mathrm{i}$ treatment during the first $24 \mathrm{hpa}$ impaired blastema formation, which could be rescued by a Smoothened agonist (Smo-A) (Fig. 6A-C and Supplementary Fig. S5). It is worth noting that Shh likely has distinct and opposite effects during healing (0-8 hpa) and during the subsequent steps of regeneration (8-24hpa) because the inhibition of regeneration is stronger when Shh is inhibited only after $8 \mathrm{hpa}$ (Fig. 6C). To more precisely examine the output of Hedgehog signaling, we analyzed the first signs of regenerative tissue, that is, (i) ROS production at $16 \mathrm{hpa}$, (ii) cell proliferation, and (iii) axon growth in the regenerating fin in the presence of $\mathrm{HH}-\mathrm{i}$. At $16 \mathrm{hpa}, \mathrm{HH}-\mathrm{i}$ strongly reduced $\mathrm{ROS}$ production (Fig. 6D-F) and cell proliferation (Fig. 6G, H), mimicking the effects of denervation (Fig. $3 \mathrm{~K}-\mathrm{N}$ ). We detected far fewer Shh-positive cells in denervated regenerating fins than in nondenervated regenerating fins (Supplementary Fig. S6). This result, which corresponds to an inhibition of Shh expression or an inhibition of the migration of Shh-expressing cells, was expected for SCs.

Next, to test whether a reduction in ROS levels could modify Shh expression, we inspected Shh-positive cells in fish incubated with a pan-NADPH oxidase inhibitor (VAS2870, Nox-i). We previously showed that Nox-i treatment significantly reduces ROS production at $6 \mathrm{hpa}$, the size of the regenerated tissue at $72 \mathrm{hpa}$, and cell proliferation at $24 \mathrm{hpa}$ (15). We therefore visualized the Shh-positive cells at $48 \mathrm{hpa}$, when they reform a specific structure at the tip of each ray, in fish challenged to regenerate in the presence of Nox-i. Under these conditions, the expression of Shh was strongly inhibited (Fig. 6I). This result suggests that ROS partially control Shh 

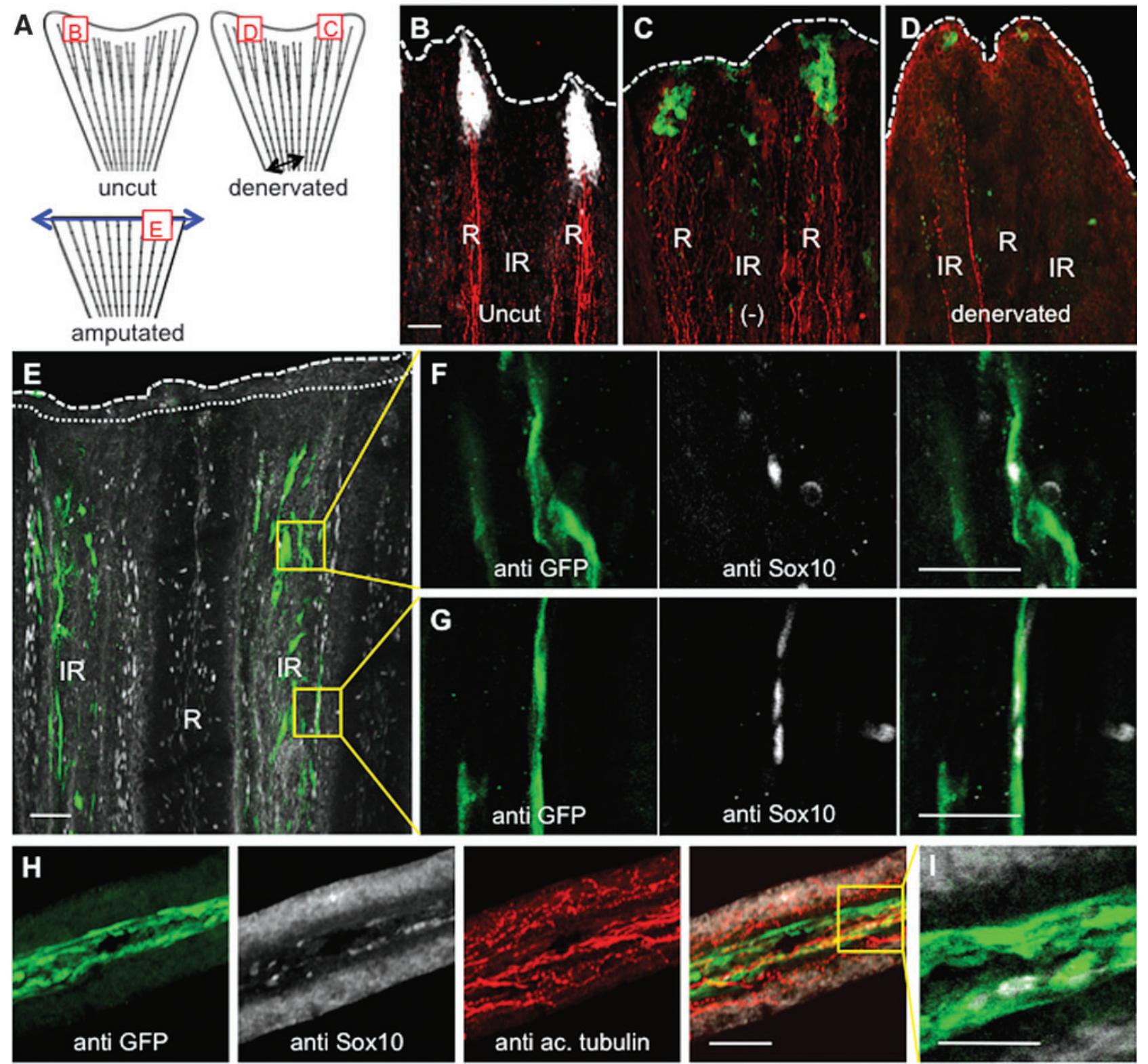

FIG. 4. Activated SCs express Shh and form a specific structure at the tip of the axon. (A) Schematic representation of the intact fin or the fin after amputation. The squares indicate the position of the acquisitions, and the letters refer to the figure panels of this figure. The dorsal part of the caudal fin was denervated (black arrow) or the fin was amputated (blue arrow). (B) Immunofluorescence staining for GFP in shh:GFP fish (white) and axon cytoskeleton $(r e d)$ in uncut fin. (C, D) Immunofluorescence staining for GFP in shh:GFP fish (green) and for the axon cytoskeleton (red) in control side (-) and denervated part of a nonamputated fin 2 days postdenervation. (E-G) Immunofluorescence staining for GFP in shh:GFP fish (green) and Sox10 (white) in the whole fin at 0.5 hpa. (F, G) Magnification of (E). (H, I) Immunofluorescence staining for GFP in shh:GFP fish (green), axon cytoskeleton (red), and Sox 10 (white) in a cryosection of a regenerating fin at $12 \mathrm{hpa}$. (I) Magnification of (H). Confocal images, 1-3 $\mu M$. Dotted line: amputation plane. Dashed line: distal part of the fin. Scale bars $=50 \mu M$ in $(\mathbf{B}-\mathbf{H})$ and $25 \mu M$ in (I). GFP, green fluorescent protein. To see this illustration in color, the reader is referred to the web version of this article at www.liebertpub.com/ars

signaling via activation of Shh transcription. Together, our results strongly suggest that nerve control of redox levels operates through activated SCs that express Shh and that redox levels also influence the Shh pathway (Fig. $7 \mathrm{H}$ ).

\section{Shh controls nerve growth through $\mathrm{H}_{2} \mathrm{O}_{2}$}

It has been demonstrated in zebrafish larvae that $\mathrm{H}_{2} \mathrm{O}_{2}$ stimulates axon growth after lesion (44). We therefore examined the nature of the ROS involved in adult ap- pendage regeneration. We already knew that NADPH oxidase inhibition impairs the process of regeneration and reduces DCFDA staining (15), which is in favor of $\mathrm{H}_{2} \mathrm{O}_{2}$. We then designed a transgenic fish expressing the HyPer biosensor for $\mathrm{H}_{2} \mathrm{O}_{2}$ (3) under a ubiquitous promoter (ubi:HyPer). The detection of $\mathrm{H}_{2} \mathrm{O}_{2}$ in regenerating fins mimicked the DCFDA staining (Fig. 7B, C), and Nox-i reduced $\mathrm{H}_{2} \mathrm{O}_{2}$ levels to the same extent as ROS levels detected with DCFDA fluorescent probe (Fig. 7D). On the contrary, Nox-i had a mild effect if any on the 


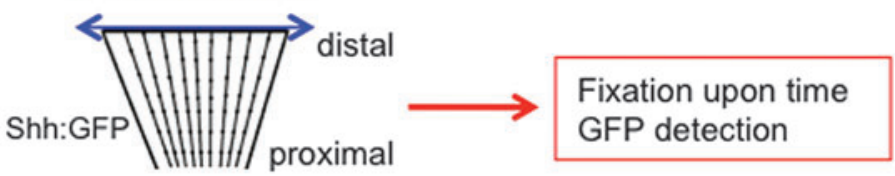

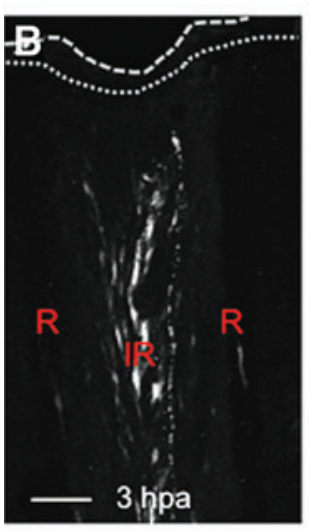
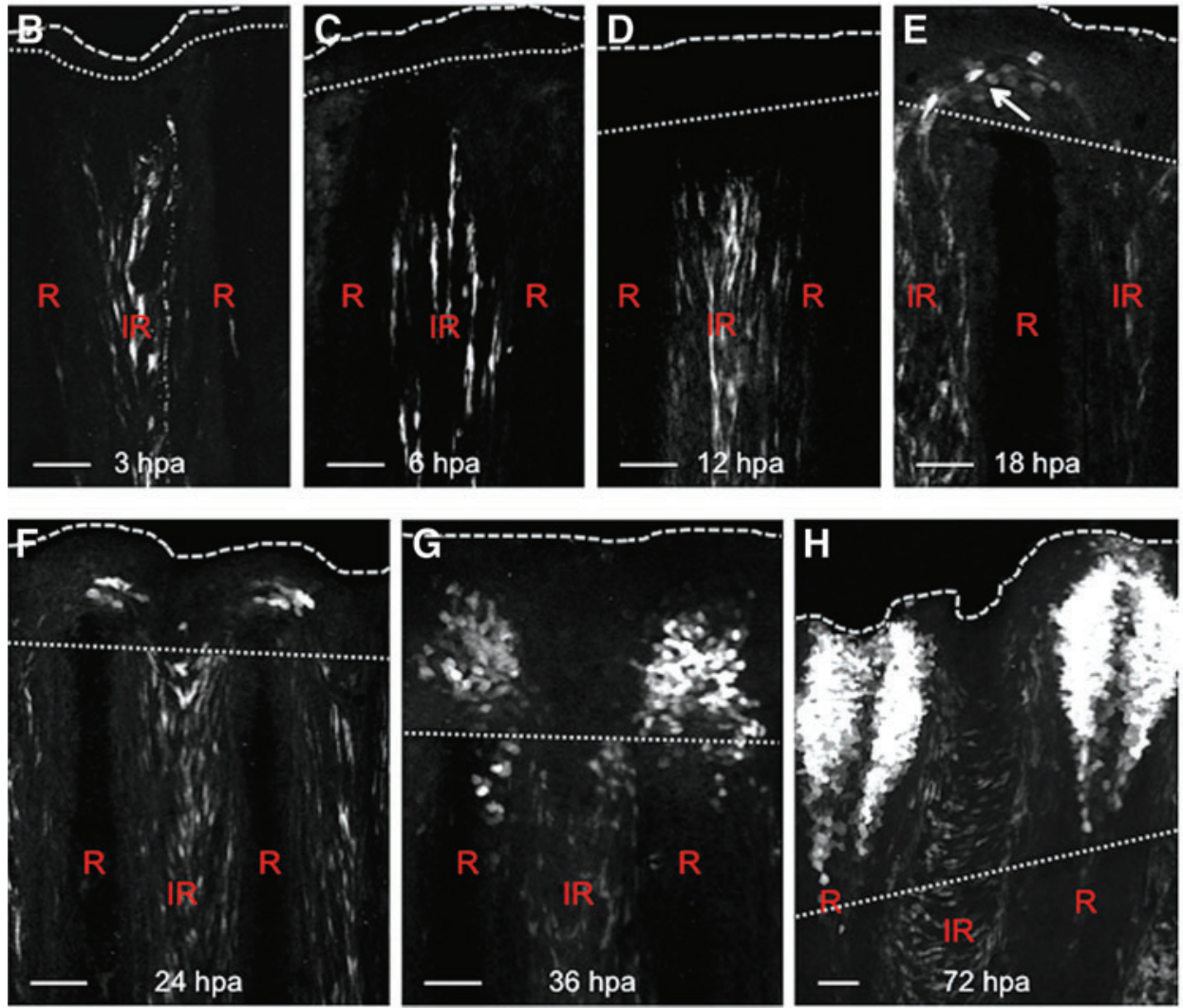

FIG. 5. Behavior of Shhexpressing cells during regeneration. (A) Cells expressing Shh were visualized during the time course of regeneration by immunodetection of the GFP in shh:GFP transgenic fish. Until $12 \mathrm{hpa}$, Shhpositive cells were detected in the inter-ray of the stump (BD). At $18 \mathrm{hpa}$, some Shhpositive cells were present at the tip of the regenerating ray (arrow) (E) and their numbers increased over time to reform the structure present in the uncut fin by 48-72 hpa (F-H). Scale bars $=50 \mu M$. Dotted line: amputation plane. $D a$ shed line: distal part of the fin. To see this illustration in color, the reader is referred to the web version of this article at www.liebertpub.com/ars mitochondrial ROS level (Supplementary Fig. S7). These experiments suggest that the ROS detected with DCFDA and involved in adult appendage regeneration is $\mathrm{H}_{2} \mathrm{O}_{2}$. We then investigated the potential role of Hedgehog signaling and $\mathrm{H}_{2} \mathrm{O}_{2}$ in nerve growth during appendage regeneration in adults. We assessed nerve growth in fish exposed to NADPH oxidase inhibition (Nox-i) or Hedgehog signaling inhibition $(\mathrm{HH}-\mathrm{i})$ during adult caudal fin regeneration (Fig. 7E-G). First, adult fish were incubated with Nox-i or $\mathrm{HH}-\mathrm{i}$ at the time of amputation, and then axon growth was scored at $24 \mathrm{hpa}$ (Fig. 7E, F). Nox-i significantly reduced axon regrowth in adults (Fig. 7F, G), which suggests a positive feedback loop by which $\mathrm{H}_{2} \mathrm{O}_{2}$ stimulates nerve growth in adults, similar to what was found in larvae. Furthermore, $\mathrm{HH}-\mathrm{i}$ inhibited axon growth to approximately the same extent as Nox-i (Fig. 7G). This last result suggests that Shh partially contributes to $\mathrm{H}_{2} \mathrm{O}_{2}$ signaling. These data identify a positive feedback loop in which $\mathrm{H}_{2} \mathrm{O}_{2}$ attracts nerves and nerves control $\mathrm{H}_{2} \mathrm{O}_{2}$ homeostasis during regeneration (Fig. 8).

\section{Discussion}

We first established that denervation abolishes the regenerative capacities of the amputated caudal fin, consis- tent with previous experiments performed on the pectoral fins of other teleost fish (16) and on newt appendages (50). We were led to examine a possible link between nerves and redox status by the demonstration that regeneration of a denervated appendage in newts can be rescued by overexpression of newt anterior gradient (nAG, AGR2 in mammals) (27), a protein disulfide isomerase that is expressed successively in SCs and in the wound epidermis. Additional results underlined the central role of this disulfide isomerase in the nerve dependence of fin regeneration: during development, $\mathrm{nAG}$ is first expressed in the epidermis, then switched off by nerve arrival, and later reinduced by the nerves themselves after lesioning (26). By contrast, prevention of appendage innervation during development leads to continuous $\mathrm{nAG}$ expression and regeneration becomes nerve independent (26). Although the relationship between ROS levels and $\mathrm{nAG}$ expression was not addressed at that time, those results pointed to the relevance of redox balance in the control of appendage regeneration by nerves.

We then proved that nerves control the dynamic redox levels in the adult fin and after amputation and that implementing this control involves SCs and Hedgehog signaling. These results support a new paradigm for the regulation of tissue homeostasis. We have identified two unexpected 
A

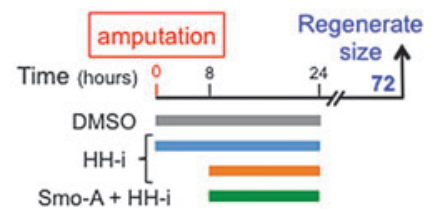

D

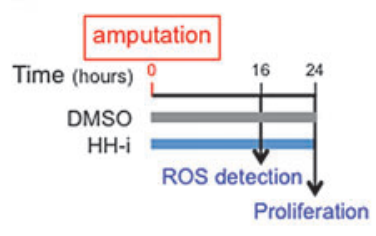

B

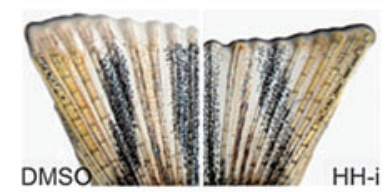

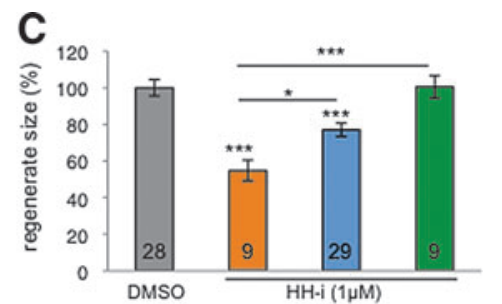

$\mathbf{E}$

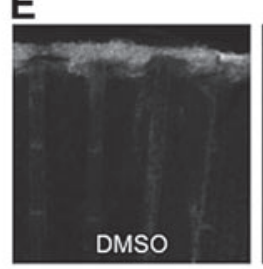

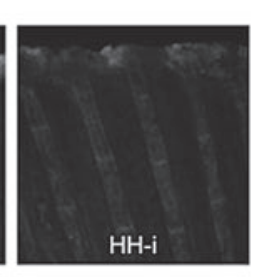

I
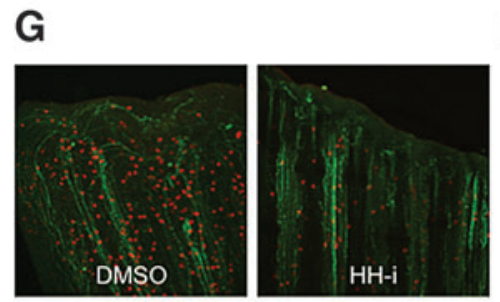

H

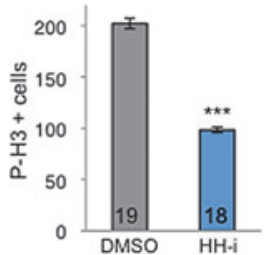

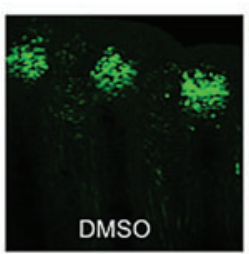
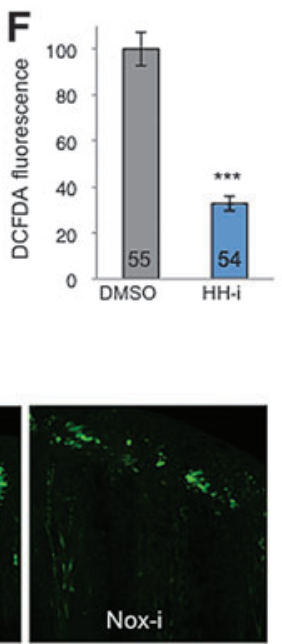

FIG. 6. Early HH signaling is necessary for ROS production. (A-C) HH-i added to the water bath from 0 to $24 \mathrm{hpa}$ (blue) or from 8 to 24 hpa (orange) inhibits regeneration, which can be rescued by Smo-A (green). (D-H) Hedgehog inhibition with HH-i (cyclopamine) (D) reduced ROS levels at the amputation plane at $16 \mathrm{hpa}(\mathbf{E}, \mathbf{F})$ and stump proliferation at $24 \mathrm{hpa}(\mathbf{G}, \mathbf{H})$. (G, H) Immunofluorescence staining for the axonal marker, acetylated tubulin (green), and for the mitotic cell marker, phosphorylated histone H3 (red). (I) Nox-i added to the water bath from 0 to 24 hpa reduced the number of Shh-positive cells detected at 48 hpa. Shhpositive cells were visualized by immunodetection of the GFP in shh:GFP transgenic fish. Error bars represent the SEM $(* p<0.05$; $* * * p<0.001) . n$ Values are indicated at the bottom of each column of the graphs. HH-i, hedgehog inhibitor, cyclopamine; Smo-A, smoothened agonist. To see this illustration in color, the reader is referred to the web version of this article at www.liebertpub.com/ars

feedback loops (Fig. 7H) between $\mathrm{H}_{2} \mathrm{O}_{2}$ and Hedgehog signaling in injured growing nerves, which cooperate to ensure tissue growth and coordination for the regeneration of a properly innervated appendage (Fig. 8). The findings that peripheral nerves control redox levels and that in turn $\mathrm{H}_{2} \mathrm{O}_{2}$ regulates nerve growth support the idea that organ size and regeneration are intimately dependent on this positive interaction.

The crowning of axons by Schwann-derived cells expressing Shh has not previously been described in vertebrates, although the importance of Hedgehog signaling in SC behavior was demonstrated a long time ago (31). In mammals, Dhh is expressed in glial cells and is a key element in maintaining peripheral nerve integrity (49). It will be interesting to determine whether Dhh is also involved in redox homeostasis and whether Dhh and Shh are commutable in SCs for ensuring nerve maintenance and regeneration. The involvement of Shh in the control of nerve growth has been known for a decade (reviewed in Bovolenta and SanchezArrones $^{5}$ and Yam and Charron ${ }^{57}$ ) and its role in neuroprotection via its secretion by SCs has also been documented (22). The importance of SCs for nerve regeneration is also well known (reviewed in Glenn and Talbot ${ }^{17}$ and Jessen et al. ${ }^{23}$ ), as is the fact that SCs are sensitive to the redox environment $(30,45,48)$. However, our results demonstrate for the first time that these different pathways are mechanistically linked by reciprocal interactions during appendage regeneration.
Our findings demonstrate the translational potential of the extracellular application of $\mathrm{H}_{2} \mathrm{O}_{2}$ in diseases involving axonal degeneration. Neuropathies are often associated with chronic wounds or tumor irradiation, and in both cases, nerve degeneration is due to miscommunication between axons and glia $(12,59)$. Manipulation of Hedgehog signaling can reverse diabetic neuropathy (8), and a few reports have addressed the involvement of $\mathrm{H}_{2} \mathrm{O}_{2}$ in this kind of neurological complication $(34,37)$. However, these studies did not consider a possible interaction of the Hedgehog pathway with $\mathrm{H}_{2} \mathrm{O}_{2}$, and our results lead for the first time to the idea that cross talk between neurons and glia operating in vertebrate regeneration involves the regulation of $\mathrm{H}_{2} \mathrm{O}_{2}$ homeostasis.

Cellular redox homeostasis mediates a plethora of cellular pathways, as indicated by the roles of ROS in cell plasticity, tissue regeneration, and wound healing, as well as the imbalance of ROS homeostasis in pathogenesis (e.g., tumorigenesis, autoimmunity, degenerative diseases, and diabetes) $(4,28,47,54$, 56). Our observations put Shh on the list of redox targets. Taking into account that Shh signaling has a central role in various human pathologies such as degenerative diseases, cancer, and autoimmunity (reviewed in Briscoe and Therond, ${ }^{6}$ Carney and Ingham, ${ }^{9}$ and Petrova and Joyner ${ }^{36}$ ), in which the balance between oxidants and antioxidants is often perturbed $(54,58)$, our results provide a new mechanism that may be of crucial importance in controlling these biological processes. Consequently, targeting the Hedgehog pathway with topical 

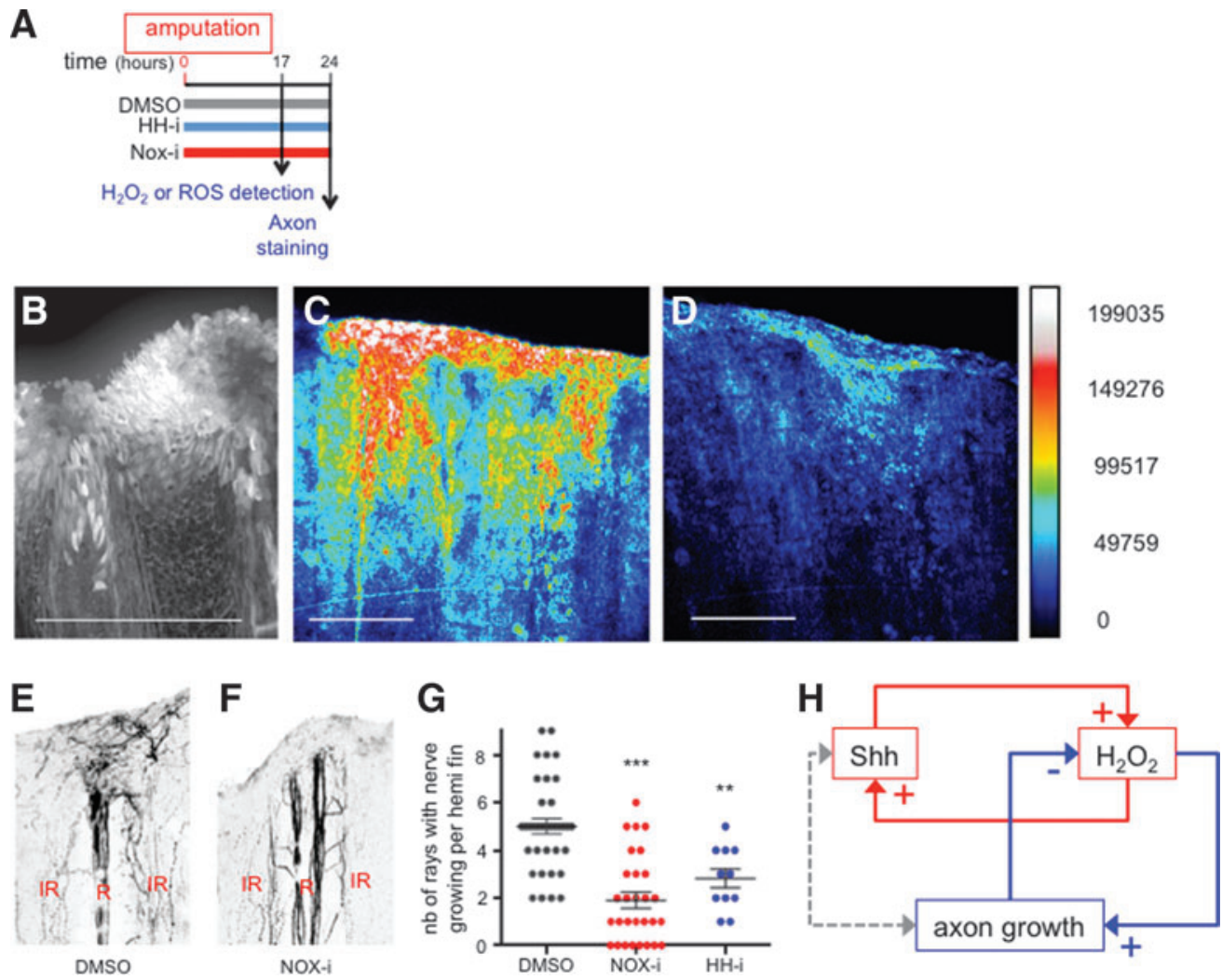

FIG. 7. $\mathrm{H}_{2} \mathrm{O}_{2}$ stimulates axon growth in a positive feedback loop. (A) Scheme of the experiments. (B) ROS detection with DCFDA fluorescent probe. (C, D) Detection of $\mathrm{H}_{2} \mathrm{O}_{2}$ in ubi:HyPer fish. Fish were incubated in water (C) or Nox-i (D) and fluorescence of HyPer analyzed on adult anesthetized fish. $\left[\mathrm{H}_{2} \mathrm{O}_{2}\right]$ is inferred from the $\mathrm{YFP}_{500} / \mathrm{YFP}_{420}$ excitation ratio of HyPer. Pseudocolor calibration bars: HyPer ratio $\left(\mathrm{YFP}_{500} / \mathrm{YFP}_{420}\right)$. (E, F) Growing nerves were detected in the regenerating fin at $24 \mathrm{hpa}$ by immunodetection of acetylated tubulin in fish incubated in vehicle (E), Nox-i (F), or HH-i (not shown). The quantification presented in $(\mathbf{G})$ corresponds to the number of rays with growing nerves per half fin (maximum 9). $n$ Values: dimethyl sulfoxide $=36 ; \mathrm{NOX}-\mathrm{i}=29 ; \mathrm{HH}-\mathrm{i}=11$. (H) This article reveals the interaction between two feedback loops in the regulation of axon growth. Error bars represent the SEM $(* * p<0.01 ; * * * p<0.001)$. Scale bars $=200 \mu M$. YFP, yellow fluorescent protein. To see this illustration in color, the reader is referred to the web version of this article at www.liebertpub.com/ars

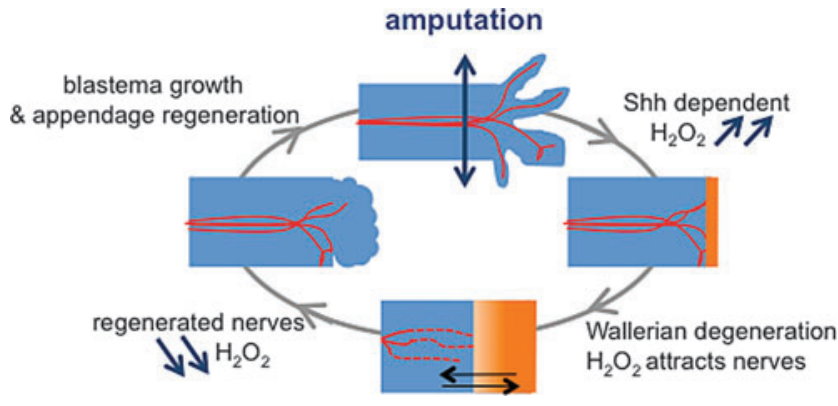

FIG. 8. Synthetic model for $\mathrm{H}_{2} \mathrm{O}_{2}$ /nerve interaction during appendage regeneration. In adults, tissues are mainly in a reduced state (top, blue). Amputation induces an increase in $\mathrm{H}_{2} \mathrm{O}_{2}$ levels (orange) that is nerve dependent and involves Shh signaling (right). Following Wallerian degeneration (dashed lines), regions of high $\mathrm{H}_{2} \mathrm{O}_{2}$ levels attract axons (red) and are essential for progenitor cell recruitment and blastema formation (bottom). $\mathrm{H}_{2} \mathrm{O}_{2}$ levels decrease upon reinnervation (left). To see this illustration in color, the reader is referred to the web version of this article at www.liebertpub.com/ars application of $\mathrm{H}_{2} \mathrm{O}_{2}$ may be a novel therapeutic strategy outside the field of peripheral neuropathy.

\section{Materials and Methods}

\section{Fish care, surgery, and quantification of regeneration}

Zebrafish colonies (AB-Tu and nacre fish) and transgenic fish [sox 10(7.2):mrfp (24) and 2.4shh:GFP:ABC\#15 (13)] were maintained using standard methods. The animal facility obtained approval from the French agreement from the Ministère de l'agriculture (No. C75-05-12), and the protocols were approved by the Ministère de l'éducation nationale de l'enseignement supérieur et de la recherche (00477.02). To maintain a healthy colony, a cycle of 14-h light-10-h dark was used, and a water temperature of $28^{\circ} \mathrm{C}$ was maintained, with a maximal density of five fish per liter. Water filtration depended on Aquatic Habitat stand-alone fish housing and operated automatically (Aquatic Habitat, Inc., Apopka, FL). Fish were fed twice per day with live 2-day-old artemia. For manipulation and amputation, the adult zebrafish (5-10 months of age) were anesthetized in $0.1 \%$ tricaine (ethyl-m-aminobenzoate), the caudal fins were amputated at the level of the first ray bifurcation and the fins were allowed to regenerate for various 
lengths of time. Denervation was performed on the dorsal part of the caudal fin using a trapezoidal microknife (Bausch \& Lomb, Rochester, NY). The efficiency of regeneration was quantified at $3 \mathrm{dpa}$. The surface of the blastema was measured and subsequently divided by the square length of the amputation plane for each fish. The efficiency of regeneration is expressed as a percentage of the control.

\section{Transgenic line}

The sequence coding for HyPer (3) was introduced into a vector suitable for transgenesis under a ubiquitous promoter (ubi) (33). The details of the cloning procedures are available upon request. Stable transgenic lines with ubiquitous expression of the fluorescent proteins were selected.

\section{ROS detection}

The compound, $2^{\prime}, 7^{\prime}$-dichlorodihydrofluorescein diacetate (H2DCFDA; Calbiochem, San Diego, CA), was used to monitor the accumulation of ROS in adult zebrafish fins. Fluorescent DCF was formed through ROS oxidation. Zebrafish were incubated with H2DCFDA $(50 \mu M) 2 \mathrm{~h}$ before confocal imaging. Spinning-disk images were acquired using a $4 \times 1$ 0.15 N.A. objective on a Nikon Eclipse Ti microscope equipped with a CoolSnap HQ2/CCD camera (Princeton Instruments, Trenton, NJ) and a CSUX1-A1 (Yokogawa, Tokyo, Japan) confocal scanner. MetaMorph software (Molecular Devices, Sunnyvale, CA) was used to collect the data. Fluorescence was excited with a $491 \mathrm{~nm}$ laser and detected with a $525 / 39 \mathrm{~nm}$ filter. Quantification of fluorescence intensity was performed using ImageJ software. Oxidation of MitoSOX ${ }^{\mathrm{TM}}$ Red (Molecular Probes, Eugene, OR) reagent by superoxide produces red fluorescence specifically targeted to mitochondria in live cells. For double detection of mitochondrial superoxide and cellular ROS, adult zebrafish were incubated with MitoSOX Red $(0.5 \mu M)$ and H2CDFDA $(50 \mu M) 2 \mathrm{~h}$ before confocal imaging. Leica SP5-MP images were acquired using a Leica PL APO $25 \times$ objective (Leica Microsystems GmbH, Wetzlar, Germany). Acquisitions were made in $1024 \times 1024$ pixels with a line average of 4 and a scanning speed of $400 \mathrm{~Hz}$. H2CDFDA acquisitions used a spectral band from 495 to $535 \mathrm{~nm}$ and MitoSOX from 610 to $750 \mathrm{~nm}$.

\section{$\mathrm{H}_{2} \mathrm{O}_{2}$ detection with the HyPer probe}

HyPer fluorescence was excited with 501/16 and 420/40 bandpass excitation filters, and the corresponding yellow fluorescent protein (YFP) emission was acquired using a 530/35 bandpass emission filter. Spinning-disk images were acquired using a $4 \times \pm-1.5 \times$ objective on a Nikon Eclipse Ti microscope (Nikon Instruments, Melville, NY) equipped with an Evolve ${ }^{\text {TM }}$ 512 EMCCD camera (Photometrics, Tucson, AZ). To calculate the HyPer ratio, images were treated as previously described (32).

\section{Immunofluorescence and imaging}

The fins were fixed in $4 \%$ paraformaldehyde overnight at $4^{\circ} \mathrm{C}$ and used for whole-mount immunohistochemistry with antiphospho-histone H3 (No. SC-8656-R; Santa Cruz Biotechnology, Inc., Dallas, TX) to detect proliferative cells, antiacetylated tubulin (No. T7451; Sigma-Aldrich, Saint Louis, MO) to detect axons, anti-GFP to detect GFP in
Shh:GFP fish (No. ab13970; Abcam, Cambridge, MA), antimCherry (No. 6332543; Clontech Laboratories, Inc., Mountain View, CA) to detect mRFP in sox10:RFP fish, and antiSox10 (No. GTX128374; GeneTex, Inc., Irvine, CA). The P$\mathrm{H} 3$-positive cells were counted in ray and inter-ray two in all segments. Immunofluorescence images were acquired using an inverted Leica SP5 with a Leica PL APO 20×/N.A. $=0.7$ oil immersion objective. For coimmunolabeling of Sox 10 and HH-positive cells, the fins were snap-frozen in optimal cutting temperature compound and sectioned at $20 \mu M$ with a cryomicrotome (No. HM560; Thermo Fisher Scientific, Waltham, MA).

\section{Pharmacological treatments}

A maximum of five adult fish were incubated in $200 \mathrm{ml}$ of water for all pharmaceutical treatments. VAS-2870 (Nox-i) was purchased from Enzo Life Sciences (No. BML-El3950010; Enzo Life Sciences, Inc., Farmingdale, NY), and cyclopamine V (HH-i) (No. 239803) and Smo-A (No. 566660) were obtained from Calbiochem and $\mathrm{H}_{2} \mathrm{O}_{2}$ from Merck Millipore (Darmstadt, Germany). Fish incubated in dimethyl sulfoxide comprised the control group. The fish were maintained in the dark and returned to the light for $1 \mathrm{~h}$ per day for feeding and water change.

\section{Statistical analysis}

Continuous variables are expressed as the mean \pm standard error of the mean. Comparisons between multiple groups were performed using one-way analysis of variance, followed by Tukey's post-tests. Comparisons between the two groups were performed using Student's $t$-tests. $p$ Values $<0.05$ were considered significant.

\section{Acknowledgments}

This work was performed in the Collège de France and benefited from Alain Prochiantz's constant support. The authors thank Matthieu Boukaissi and Tiphaine Vallée for technical assistance and Bruce Appel and Uwe Strähle for sharing the transgenic lines used in this work. The authors benefited from fruitful discussions with Alain Joliot and Piotr Topilko. This work was supported by the program "Investissements d'Avenir" launched by the French Government and implemented by the ANR, with the references ANR-10-LABX-54 MEMO LIFE-ANR-11-IDEX-0001-02 Paris sciences et Lettres (PSL) Research University.

\section{Author Disclosure Statement}

No competing financial interests exist.

\section{References}

1. Bai H, Zhang W, Qin XJ, Zhang T, Wu H, Liu JZ, and Hai CX. Hydrogen peroxide modulates the proliferation/quiescence switch in the liver during embryonic development and posthepatectomy regeneration. Antioxid Redox Signal 22: 921-937, 2015.

2. Bauer G. Targeting extracellular ROS signaling of tumor cells. Anticancer Res 34: 1467-1482, 2014.

3. Belousov VV, Fradkov AF, Lukyanov KA, Staroverov DB, Shakhbazov KS, Terskikh AV, and Lukyanov S. Genetically encoded fluorescent indicator for intracellular hydrogen peroxide. Nat Methods 3: 281-286, 2006. 
4. Bigarella CL, Liang R, and Ghaffari S. Stem cells and the impact of ROS signaling. Development 141: 4206-4218, 2014.

5. Bovolenta $\mathrm{P}$ and Sanchez-Arrones L. Shh goes multidirectional in axon guidance. Cell Res 22: 611-613, 2012.

6. Briscoe $J$ and Therond PP. The mechanisms of hedgehog signalling and its roles in development and disease. Nat Rev Mol Cell Biol 14: 416-429, 2013.

7. Brownell I, Guevara E, Bai CB, Loomis CA, and Joyner AL. Nerve-derived sonic hedgehog defines a niche for hair follicle stem cells capable of becoming epidermal stem cells. Cell Stem Cell 8: 552-565, 2011.

8. Calcutt NA, Allendoerfer KL, Mizisin AP, Middlemas A, Freshwater JD, Burgers $M$, Ranciato R, Delcroix JD, Taylor FR, Shapiro R, Strauch K, Dudek H, Engber TM, Galdes A, Rubin LL, and Tomlinson DR. Therapeutic efficacy of sonic hedgehog protein in experimental diabetic neuropathy. J Clin Invest 111: 507-514, 2003.

9. Carney TJ and Ingham PW. Drugging hedgehog: signaling the pathway to translation. BMC Biol 11: 37, 2013.

10. Chen ZL, Yu WM, and Strickland S. Peripheral regeneration. Annu Rev Neurosci 30: 209-233, 2007.

11. Covarrubias L, Hernandez-Garcia D, Schnabel D, SalasVidal E, and Castro-Obregon S. Function of reactive oxygen species during animal development: passive or active? Dev Biol 320: 1-11, 2008.

12. Delanian S, Lefaix JL, and Pradat PF. Radiation-induced neuropathy in cancer survivors. Radiother Oncol 105: 273 282, 2012.

13. Ertzer R, Muller F, Hadzhiev Y, Rathnam S, Fischer N, Rastegar S, and Strahle U. Cooperation of sonic hedgehog enhancers in midline expression. Dev Biol 301: 578-589, 2007.

14. Finkel T. Signal transduction by reactive oxygen species. $J$ Cell Biol 194: 7-15, 2011.

15. Gauron C, Rampon C, Bouzaffour M, Ipendey E, Teillon J, Volovitch M, and Vriz S. Sustained production of ROS triggers compensatory proliferation and is required for regeneration to proceed. Sci Rep 3: 2084, 2013.

16. Geraudie J and Singer M. Necessity of an adequate nerve supply for regeneration of the amputated pectoral fin in the teleost Fundulus. J Exp Zool 234: 367-374, 1985.

17. Glenn TD and Talbot WS. Signals regulating myelination in peripheral nerves and the Schwann cell response to injury. Curr Opin Neurobiol 23: 1041-1048, 2013.

18. Gorrini C, Harris IS, and Mak TW. Modulation of oxidative stress as an anticancer strategy. Nat Rev Drug Discov 12: 931-947, 2013.

19. Hadzhiev Y, Lele Z, Schindler S, Wilson SW, Ahlberg P, Strahle U, and Muller F. Hedgehog signaling patterns the outgrowth of unpaired skeletal appendages in zebrafish. BMC Dev Biol 7: 75, 2007.

20. Han P, Zhou XH, Chang N, Xiao CL, Yan S, Ren H, Yang XZ, Zhang ML, Wu Q, Tang B, Diao JP, Zhu X, Zhang C, $\mathrm{Li}$ CY, Cheng $\mathrm{H}$, and Xiong JW. Hydrogen peroxide primes heart regeneration with a derepression mechanism. Cell Res 24: 1091-1107, 2014.

21. Harsum S, Clarke JD, and Martin P. A reciprocal relationship between cutaneous nerves and repairing skin wounds in the developing chick embryo. Dev Biol 238: 27 39, 2001.

22. Hashimoto M, Ishii K, Nakamura Y, Watabe K, Kohsaka S, and Akazawa C. Neuroprotective effect of sonic hedgehog up-regulated in Schwann cells following sciatic nerve injury. J Neurochem 107: 918-927, 2008.
23. Jessen KR, Mirsky R, and Lloyd AC. Schwann cells: development and role in nerve repair. Cold Spring Harb Perspect Biol 7: a020487, 2015.

24. Kucenas S, Takada N, Park HC, Woodruff E, Broadie K, and Appel B. CNS-derived glia ensheath peripheral nerves and mediate motor root development. Nat Neurosci 11: 143-151, 2008.

25. Kumar A and Brockes JP. Nerve dependence in tissue, organ, and appendage regeneration. Trends Neurosci 35: 691-699, 2012.

26. Kumar A, Delgado JP, Gates PB, Neville G, Forge A, and Brockes JP. The aneurogenic limb identifies developmental cell interactions underlying vertebrate limb regeneration. Proc Natl Acad Sci U S A 108: 13588-13593, 2011.

27. Kumar A, Godwin JW, Gates PB, Garza-Garcia AA, and Brockes JP. Molecular basis for the nerve dependence of limb regeneration in an adult vertebrate. Science 318: 772$777,2007$.

28. Loo AE, Wong YT, Ho R, Wasser M, Du T, Ng WT, and Halliwell B. Effects of hydrogen peroxide on wound healing in mice in relation to oxidative damage. PLoS One 7: e49215, 2012.

29. Love NR, Chen Y, Ishibashi S, Kritsiligkou P, Lea R, Koh Y, Gallop JL, Dorey K, and Amaya E. Amputation-induced reactive oxygen species are required for successful Xenopus tadpole tail regeneration. Nat Cell Biol 15: 222-228, 2013.

30. Lu C, Schoenfeld R, Shan Y, Tsai HJ, Hammock B, and Cortopassi G. Frataxin deficiency induces Schwann cell inflammation and death. Biochim Biophys Acta 1792: 1052-1061, 2009.

31. Mirsky R and Jessen KR. The neurobiology of Schwann cells. Brain Pathol 9: 293-311, 1999.

32. Mishina NM, Markvicheva KN, Bilan DS, Matlashov ME, Shirmanova MV, Liebl D, Schultz C, Lukyanov S, and Belousov VV. Visualization of intracellular hydrogen peroxide with HyPer, a genetically encoded fluorescent probe. Methods Enzymol 526: 45-59, 2013.

33. Mosimann C, Kaufman CK, Li P, Pugach EK, Tamplin OJ, and Zon LI. Ubiquitous transgene expression and Crebased recombination driven by the ubiquitin promoter in zebrafish. Development 138: 169-177, 2011.

34. Papanas $\mathrm{N}$ and Ziegler D. Efficacy of alpha-lipoic acid in diabetic neuropathy. Expert Opin Pharmacother 15: 27212731, 2014.

35. Parrinello S, Napoli I, Ribeiro S, Wingfield Digby P, Fedorova M, Parkinson DB, Doddrell RD, Nakayama M, Adams RH, and Lloyd AC. EphB signaling directs peripheral nerve regeneration through Sox2-dependent Schwann cell sorting. Cell 143: 145-155, 2010.

36. Petrova R and Joyner AL. Roles for hedgehog signaling in adult organ homeostasis and repair. Development 141: 3445-3457, 2014.

37. Pop-Busui R, Stevens MJ, Raffel DM, White EA, Mehta M, Plunkett CD, Brown MB, and Feldman EL. Effects of triple antioxidant therapy on measures of cardiovascular autonomic neuropathy and on myocardial blood flow in type 1 diabetes: a randomised controlled trial. Diabetologia 56: 1835-1844, 2013.

38. Poss KD, Keating MT, and Nechiporuk A. Tales of regeneration in zebrafish. Dev Dyn 226: 202-210, 2003.

39. Quint E, Smith A, Avaron F, Laforest L, Miles J, Gaffield $\mathrm{W}$, and Akimenko MA. Bone patterning is altered in the regenerating zebrafish caudal fin after ectopic expression of 
sonic hedgehog and bmp2b or exposure to cyclopamine. Proc Natl Acad Sci U S A 99: 8713-8718, 2002.

40. Rampon C, Gauron C, Meda F, Volovitch M, and Vriz S. Adenosine enhances progenitor cell recruitment and nerve growth via its A2B receptor during adult fin regeneration. Purinergic Signal 10: 595-602, 2014.

41. Reczek CR and Chandel NS. ROS-dependent signal transduction. Curr Opin Cell Biol 33: 8-13, 2015.

42. Reimer MM, Kuscha V, Wyatt C, Sorensen I, Frank RE, Knuwer M, Becker T, and Becker CG. Sonic hedgehog is a polarized signal for motor neuron regeneration in adult zebrafish. J Neurosci 29: 15073-15082, 2009.

43. Rhee SG. Cell signaling. $\mathrm{H} 2 \mathrm{O} 2$, a necessary evil for cell signaling. Science 312: 1882-1883, 2006.

44. Rieger $S$ and Sagasti A. Hydrogen peroxide promotes injury-induced peripheral sensory axon regeneration in the zebrafish skin. PLoS Biol 9: e1000621, 2011.

45. Sato K, Yama K, Murao Y, Tatsunami R, and Tampo Y. Epalrestat increases intracellular glutathione levels in Schwann cells through transcription regulation. Redox Biol 2: 15-21, 2013.

46. Scheib $\mathrm{J}$ and Hoke A. Advances in peripheral nerve regeneration. Nat Rev Neurol 9: 668-676, 2013.

47. Schieber M and Chandel NS. ROS function in redox signaling and oxidative stress. Curr Biol 24: R453-R462, 2014.

48. Shan Y, Schoenfeld RA, Hayashi G, Napoli E, Akiyama T, Iodi Carstens M, Carstens EE, Pook MA, and Cortopassi GA. Frataxin deficiency leads to defects in expression of antioxidants and Nrf2 expression in dorsal root ganglia of the Friedreich's ataxia YG8R mouse model. Antioxid Redox Signal 19: 1481-1493, 2013.

49. Sharghi-Namini S, Turmaine M, Meier C, Sahni V, Umehara F, Jessen KR, and Mirsky R. The structural and functional integrity of peripheral nerves depends on the glial-derived signal desert hedgehog. J Neurosci 26: 6364-6376, 2006.

50. Singer M. Trophic functions of the neuron. VI. Other trophic systems. Neurotrophic control of limb regeneration in the newt. Ann N Y Acad Sci 228: 308-322, 1974.

51. Sirko S, Behrendt G, Johansson PA, Tripathi P, Costa M, Bek S, Heinrich C, Tiedt S, Colak D, Dichgans M, Fischer IR, Plesnila N, Staufenbiel M, Haass C, Snapyan M, Saghatelyan A, Tsai LH, Fischer A, Grobe K, Dimou L, and Gotz M. Reactive glia in the injured brain acquire stem cell properties in response to sonic hedgehog. [corrected]. Cell Stem Cell 12: 426-439, 2013.

52. Stelnicki EJ, Doolabh V, Lee S, Levis C, Baumann FG, Longaker MT, and Mackinnon S. Nerve dependency in scarless fetal wound healing. Plast Reconstr Surg 105: 140-147, 2000.

53. Ushio-Fukai M and Rehman J. Redox and metabolic regulation of stem/progenitor cells and their niche. Antioxid Redox Signal 21: 1587-1590, 2014.

54. van der Vliet A and Janssen-Heininger YM. Hydrogen peroxide as a damage signal in tissue injury and inflammation: murderer, mediator, or messenger? J Cell Biochem 115: 427-435, 2014.

55. Wang J, Cao J, Dickson AL, and Poss KD. Epicardial regeneration is guided by cardiac outflow tract and Hedgehog signalling. Nature 522: 226-230, 2015.

56. Watson JD. Type 2 diabetes as a redox disease. Lancet 383 : 841-843, 2014.

57. Yam PT and Charron F. Signaling mechanisms of nonconventional axon guidance cues: the Shh, BMP and Wnt morphogens. Curr Opin Neurobiol 23: 965-973, 2013.
58. Ye ZW, Zhang J, Townsend DM, and Tew KD. Oxidative stress, redox regulation and diseases of cellular differentiation. Biochim Biophys Acta 1850: 1607-1621, 2014.

59. Zenker J, Ziegler D, and Chrast R. Novel pathogenic pathways in diabetic neuropathy. Trends Neurosci 36: 439449, 2013.

60. Zhang J, Jeradi S, Strahle U, and Akimenko MA. Laser ablation of the sonic hedgehog-a-expressing cells during fin regeneration affects ray branching morphogenesis. Dev Biol 365: 424-433, 2012.

61. Zhao H, Feng J, Seidel K, Shi S, Klein O, Sharpe P, and Chai Y. Secretion of shh by a neurovascular bundle niche supports mesenchymal stem cell homeostasis in the adult mouse incisor. Cell Stem Cell 14: 160-173, 2014.

Address correspondence to Prof. Sophie Vriz

Centre Interdisciplinaire de Recherche en Biologie (CIRB) CNRS UMR 7241/INSERM U1050/Collège de France

11, Place Marcelin Berthelot 75231 Paris

France

E-mail:vriz@univ-paris-diderot.fr

Date of first submission to ARS Central, May 15, 2015; date of final revised submission, September 17, 2015; date of acceptance, October 6, 2015.

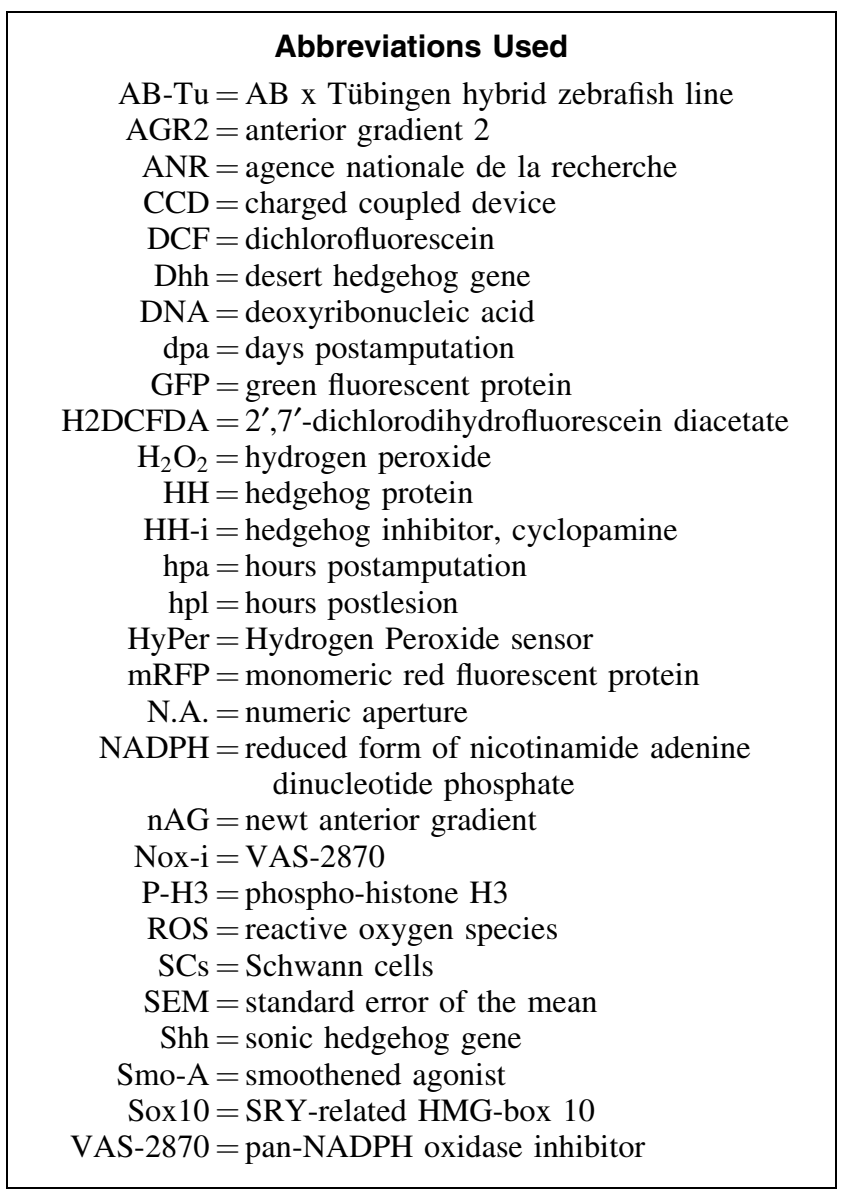

